\title{
Qualitative and Quantitative Debates in Contemporary Educational
} Research

\author{
Muftahu Jibirin Salihu \\ School of Educational Studies, \\ Universiti Sains Malaysia, Malaysia.
}

\section{ABSTRACT:}

This research paper will begin with philosophically exploring the saying "The Researcher You Are Is The Person You Are". This provide an insight on the views and the perspectives of the researcher on the research as a subject. Subsequently, the other contents of the paper are divided into two major sections. The first section discusses the Qualitative and Quantitative philosophical and theoretical debates in contemporary educational research; Qualitative and Quantitative approaches in educational research; Objectivity and Subjectivity in educational research; Links between Data Collection and Data Analysis in educational research. The second part of the paper discussed the action research in education and the reflection of the person you are is the researcher you are in educational research settings. Finally, the paper conclude that there is no single formula when it comes to conducting research in education, each and every researcher regardless of his or her area of study would always be conducting research based on what he or she thinks and deems is the best research paradigm and method to adopt. However, there are some confident guiding principles that their application guarantee effectiveness to a certain degree in educational research.

Keywords: Qualitative, Quantitative, Objectivity, Subjectivity, Data Collection, Data Analysis, Action Research, Educational Research

\subsection{Introduction}

I have always believed that one of the most difficult things to search and find out about is the "self". Ever since I was young, I have constantly asked myself who the real "me" is and what my purpose in life is. As an educator and a researcher, I have already gone through a lot of learning processes and although I have grown enough in terms of knowledge, experience and expertise in my own field of study, I still could not figure out 'entirely' what kind of a person I $\mathrm{am}$ and what distinguishes me from another human being. Personally, I believe that every person that exists in this world is unique and highly-distinctive from another being; however, my curiosity always pushes me to explore further the evidence and manifestations of this so-called 'uniqueness' that every person has.

This even left me wondering if a person may be identified by the way he or she speaks or by the way he or she writes. As an educator, I believe that the mind is a rich source of knowledge that may possibly identify or determine who a person is. This is because everything that we come to know and believe is constructed and stored inside our minds. Eventually, what we know and believe becomes the person that we are. Knowledge slowly shapes our persona and our characters as knowledge heavily influences and molds our individual beliefs and principles. In this paper, I will be providing evidence and proof with regard to the philosophical assertion which states that "the researcher you are is the person you are". I will also be discussing in detail the following philosophical and theoretical debates in contemporary educational research which include (1) the objectivity and subjectivity in educational research, (2) the qualitative and quantitative approaches to educational research and the possibility of mixed methods and (3) the links between data collection and data analysis in educational research. Moreover, in the second part of the paper, two specific research methods will include discussions on the historical development and the contemporary applications of the two selected methods. Within the discussions, I will be incorporating my own professional beliefs, principles and personal views regarding educational research methodologies. This is why I can very well relate with the statement, "the researcher you are is the person you are" (Gale, 1998).

In the philosophical context, the above-given statement resonates the "Know thyself" which is a famous Greek aphorism. This means that one first has to know his real self before being able to identify his personal identity as a researcher. Because of this, it would be worth arguing that educators and the educational researchers need to be conscious and aware of their "axiological beliefs" as these would explain their epistemological and ontological assumptions (Pring, 2004). It would indeed be quite useful if, as a teacher and a researcher, one is able to identify some of his ontological and epistemological assumptions in connection to teaching and learning as these would reflect the kind of person the teacher or the researcher is.

For example, in my case I believe that learning is closely linked to experience. In fact, I believe that learning is best achieved through experience in the same way that research is best applied through experience rather than theoretical assumptions. I have acquired this belief that learning goes hand in hand with experience due to my personal experiences in learning when I was young. During my early years in school, I never appreciated boring lectures that are full of theories and abstract ideas which the teacher taught daily. We were always tasked to memorize many things that we did not fully understand as students.

This experience actually made me question the traditionally methods of learning and acquiring knowledge. As a student, I could not really classify myself as a "book-smart" type of student because when I was younger, I hated books. I disliked 
reading and hated memorizing facts and information. It was only during college that I honestly began appreciating theoretical knowledge and principles and this further intensified until such time that I pursued my specialization course and finished it. Because of this experience, I can honestly say that I am more of a "doer" when it comes to learning. I do not really like being a passive learner who simply reads and barely applies what he has learned.

I believe that it would always be more effective to learn and acquire knowledge when you yourself have experienced it. This does not mean however that knowledge acquisition by means of theories has to be neglected or ignored altogether. It is my personal belief that in order for learning to be effective and complete, the learner has to strike the right balance between learning through theories and learning through experience. This has been my open view on learning which I also apply in my research experiences. This is precisely the reason why I am attracted to action-type of researches and ethnographic researches which are more of action-oriented researches as opposed to simply gathering data and theories from secondary sources.

In the succeeding sections of this research paper, we will get to know more about my epistemological, axiological and ontological beliefs in learning and how this relates to my views as a researcher as well as the debatable philosophical and theoretical debates on the statement: "the researcher you are is the person you are".

\subsection{Objectivity and Subjectivity in Educational Research}

Knowing who the person conducting the research is proves to be very important and relevant in the field of educational research. This is primarily because often times, debates, concerns and issues arise with regard to the objectivity and subjectivity of the information or the data gathered within the field. According to Clark (1994) the issue on objectivity and subjectivity in educational research is quite problematic and as such, warrants special philosophical attention. Based on its definition, the concept of "objectivity" pertains to the simple act of being objective, accurate or "bias-free". In educational research the information, data or facts are not influenced by the researcher. The concept of 'subjectivity' on the other hand, involves a person's interpretation on an internal reality as opposed to simply sticking to the pure independent and external facts (Somekh \& Lewin, 2011; Richards, 2003).

The reason why objectivity and subjectivity is considered an important debatable issue in the field of educational research is due to the fact that various authors and researchers argue differently in regard to the application of objectivity and subjectivity in qualitative research. For instance, some authors like Richards (2003) agree that a certain amount of subjectivity in qualitative research may lead to equally valid results while other authors encourage only the use of objectivity in research (Freimuth, 2009). Similar to Richards, Merriam (2001) also argues that subjective research also has its value in the sense that it is capable of explaining a social phenomenon which people have constructed or created for themselves (Merriam, 2001).

As an educator and teacher, I personally believe that while subjectivity may help a researcher make sense of certain hypotheses and theories, educational researcher must still be founded on objective research comprised of pure and accurate facts and information. This does not mean that automatically equates educational research with scientific research and scientific research with objectivity and thus holds a "realist ontology" or the belief that "it is possible to 'know' the world around you". What I am simply trying to point out is that in educational research, there must be a balance on the use of objectivity and subjectivity.

Nevertheless, on one hand, I have this personal belief also that educational research, which is somewhat related to the scientific type of research and is done on the various problems and issues faced by the educational field, has to stick on the objective facts and not on subjective assumptions (Freimuth, 2009; Wallen \& Fraenkel, 2001). In stating this assertion, I admit that I believe in the possibility of knowing 'facts', that is, that there are certain pieces of data that are able to be collected that are not influenced by personal bias. I am also implying that I also hold this belief that subjective data could be aligned with 'assumptions' mostly, although from a critical research perspective, this may or may also not hold true.

\subsection{Qualitative and Quantitative Approaches to Educational Research}

Another common issue on the field of educational research is with regard to the qualitative and quantitative approaches. As an educator and teacher, I commonly utilize these two approaches in my field of study simultaneously. According to Moody (2002), quantitative research consists of collecting numerical data and performing analysis by means of different statistical methods. Apparently, this type of research data is mostly utilized on objective types of studies. On the other hand, qualitative research methodologies pertain to the act of gathering data that proves to be qualitative in terms of nature, that is, comprised of data or information which cannot be measured in terms of numerical values and/or equivalents. This usually applies to case studies and observation type of studies which typically require the use of the subjective approach (Moody, 2002; Freimuth, 2009; Gibson et al., 2008).

Nevertheless, in selecting which research approach to use, an issue comes into the picture as there are debates among researchers in regard to which approach is most appropriate to use. According to Freimuth (2009), positivism basically underpins the application of quantitative methods in social sciences while constructivism favours the qualitative methods (Somekh \& Lewin, 2005). Thus, amidst this debate on which approach to use best, the decision rests on the hands of the researcher, that is, in consideration to the research purpose, context, nature and goals that the research study is trying to achieve.

I know based from experience that educational research is mostly conducted within dynamic settings as facilitated by researchers that are actively and personally involved with their research participants and with the research contents. When we say dynamic, it is a setting wherein teachers are not allowed to teach the same lessons as well as apply the same teaching methods (Freimuth, 2009; Somekh \& Lewin, 2005). As an educator, I am always reminded of the statement 
"the researcher you are is the person you are" and this is primarily reflected in my methods of collecting data within my own research setting. Honestly, I am inclined to use more of the qualitative data approach such as observations, anecdotes, records, and other valuable source of information when it comes to conducting research studies. This is because my personal objectivist stance relies more on the facts and principles that I read from authoritative and reliable sources and references.

However, as a researcher, I also need to utilize quantitative data as well in order to substantiate the qualitative data that I have collected as well as increase my confidence on the epistemology and methodology of my research framework. Good thing is that since I have learned the value of balancing the use of qualitative and quantitative data in conducting research within setting, I have also learned the value of utilizing the mixed method approach in data collection and analysis (Somekh \& Lewin, 2005; Mackenzie \& Knipe, 2006; Plano Clark \& Creswell, 2008). The mixed method approach appeals more to me as a researcher mainly because it is the only approach that best captures the essence of the qualitative and quantitative research approaches. Although it may appear somewhat challenging to apply in certain cases, the mixed method approach adds more strength to the research as it makes use of various methods in research. Another benefit that I like about the mixed method approach is that it improves the accuracy and reliability of the research data results.

\subsection{Links between Data Collection and Data Analysis in Educational Research}

Along the process of finding out how to philosophically link research and my profession, I have come to an important realization that the researcher you are also reveals not only the type of research approach that you utilize but also the data collection and data analysis methodologies that you employ. Often times, the approach in collecting data determines the method for analyzing the data and that serves as the link between the two. For example, if a researcher applied the qualitative research approach, then most likely, the researcher would also apply qualitative means of analyzing research data such as content analysis for data derived from in-depth interviews (Somekh \& Lewin, 2005; Freimuth, 2009). What I am simply saying is that a researcher that employs a specific type of research approach would more likely apply the same type of analytical approach that suits the best method to analyze the gathered data. For example, qualitative data needs to be assessed using qualitative means while quantitative data needs to be assessed using quantitative means.

In conducting any type of educational research, it is very important for a person to evaluate the kind of researcher he or she is in order to determine his or her personal research biases and address these. A researcher's approach to any research question is influenced by his or her personal history, beliefs, existence and personality (Somekh \& Lewin, 2005; Freimuth, 2009). Therefore, if a researcher would inevitably be influenced by his past experiences and existing beliefs, personality and principles, then it would be safe to argue that there is no right way when it comes to conducting research. In the same way, there is really no single method or means of collecting and analyzing data.

For example, I can have a strong objective stance and use both quantitative and qualitative methodology or either of the two depending on my personal judgement on which research approach best applies on a specific research study. To me, there is really no problem when a person with an objective stance makes use of a quantitative research methodology or adopts a qualitative research methodology as I have previously asserted, there is really no right way when it comes to conducting research or single formula in conducting research that best fits a person with either a subjective or objective stance. Any research can go both or either ways depending on his personal judgment on what best research methodology fits the case study scenario.

\subsection{Action Research and Application in Educational Research}

One of the most interesting research methods that apply to my personality and role as an educator or a teacher is action research. According to Richardson (2001), action research may be pertained to as "participatory" action research which is a reflective type of process that aims to progressively solve problems within teams or within a community of practice. It was Kurt Lewin, a professor and social psychologist, who coined the term "action research" and referred to it as a comparative type of research that delves into the conditions as well as effects of the different forms of 'social action', by means of the spiral of steps. This is basically comprised of a circle of action, planning as well as fact-finding in regard to the results of an action (James, Milenkiewicz, \& Bucknam, 2007).

Cresswell (2008) on the other hand identified its four specific steps as the following: (1) planning, (2) acting, (3) observing, and (4) reflecting. The action research may also literally mean 'action research' due to the fact that the work needed to be fulfilled in this research did not separate the investigation needed to be conducted in solving the problem (McFarland and Stansell, 1993). Over the years, the proponents of action research have collaboratively made an effort to use this method and turn it into something more change-orientated, political and collaborative. Interestingly, there has indeed emerged, a new type of participatory action research which is considered part of a dialogue and is aimed in making critiques on the process by means of reflexivity, reflection and collaborative discussions (Kemmis and McTaggart, 2005).

In the University where I am teaching, I am presently involved in a community work intended to develop the professional English teachers in selected high schools within the town. I was assigned by our faculty division to head this community service project as a city-wide strategy of the local government in partnership with our university to be able to improve our teaching and learning process. Since I was assigned as Project Head for this very important community service project, I constantly thought of ways to assist these English teachers in helping them improve their language learning and teaching within the high schools they serve.

In order to accomplish this aim, I had to actively collaborate with these English teachers and find out, assess, as well as gain understanding of their individual school contexts wherein the education process takes place. Based on my personal experience, the participatory action research enabled me to gather direct community inputs from these target individuals 
which helped me address their needs. By means of this academic type of research which is the action research, I was able to bridge cultural gaps, increase the involvement of even the marginalized communities as well as improve the validity and quality of the research conducted. I was also able to successfully engage local theory along with the action research I directly employed.

But the real question is, where do I fit in terms of my general characteristics as a researcher in relation to action research? As I have previously stated in the beginning of this research paper, I consider myself as more of a "doer" when it comes to learning. I do not like being a passive learner who simply reads and barely applies what he has learned and I believe that this explains the kind of researcher that I am. Since I am the "doer" type of researcher with an objective stance, I like validating more on the theories, learnings and knowledge that I have acquired. I do not rely too much on theoretical assumptions but this does not mean that I totally reject subjectivity. I would like to clarify that I do not automatically consider as subjective, all types of theoretical assumptions about certain things.

In addition, being the "doer" type of researcher with an objective stance does not mean that I am more of a qualitative type of researcher or a quantitative type of researcher. This is because I am neither of the two. I have always been a researcher that freely advocates the mixed methods approach because of my perceived benefits and advantages in using this type of research method. Nevertheless, I also utilize the action research method because of my personal belief that research must involve action or any worthwhile form of activity.

Just like my personal belief in learning, I also believe that in order for a researcher to become effective and complete, the researcher has to know how to properly strike the right balance when it comes to making use of various kinds of research methods. Personally, there are case study scenarios when I had to let go of my objective stance and assume a subjective stance in research. Such cases vary depending on what is being asked and what is needed to address the problem on the research study. But in most cases, I am more of an action-oriented type of researcher who is fond of participatory action researches and ethnographic researches as opposed to the simple research approaches that require simple data gathering from secondary sources.

\subsection{Reflection of the Researcher You Are Is the Person You Are In Educational Research}

The researcher you are is reflected on your personal choice of a research approach out of a wide variety of research methodologies that prove to be relevant and appropriate with your area of research enquiry. But more than that, your choice of a research approach also reflects, in a deeper sense, the person you are as it manifests how you see the entire world and how you make decisions within the process of addressing research questions (Somekh \& Lewin, 2005). Despite the fact that conducting research really has no single formula, every researcher still works in unique and very recognizable research paradigms. As a person, I am certain that the world of reality, in the perspective of another person, is based on a lot of factors; that includes mostly the influence of social construction by means of human phenomena and human experience.

Based on my experiences in conducting various types of researches in the past, an individual's research paradigm and research methods work together in forming a specific research study. For instance, action research which is a type of research method is underpinned by constructivism, an epistemological structure. Throughout my teaching practices, I always use and apply a 'constructivist' approach by allowing an intervention within a research setting. In addition, a specific theory is also developed out of patterns of meaning (Mackenzie \& Knipe, 2006).

One thing that I personally like about action research is that it focuses and emphasizes on what it offers to its clients within professional settings. Another thing that I like about action research is that it allows personal professional growth to develop further. Since I have this innate passion to be the best person I can be in regard to my personal vocation, I enjoy employing this research method. This type of research satisfies my thirst and pursuit for a greater level of knowledge as well as a deeper level of understanding regarding my own teaching practices. This desire, which is burning deep inside of me as an educator and a teacher, motivates me to serve communities and be of use in the attainment of the growth of the various groups of people. The third thing that I like about action research is that it enables me to literally participate and engage in social actions that is meant for combatting oppression and increasing our commitment towards social betterment. This type of research study is undoubtedly motivational not only on the part of the person conducting the research but also on the ones benefitting from the experience. This is because this type of research provides a good learning environment wherein the beneficiaries of community projects get to feel comfortable as well as get to take risks in their learning without any form of fear or holding back (James, Milenkiewicz, \& Bucknam, 2007).

Similar to other types of methods, action research is capable of generating new kinds of knowledge, promoting change and improving practice. Through its systematic and planned action research process, teachers and educators like myself may be able to challenge certain assumptions by means of gathering systematic data analysis and collection. It enables the researcher to also have a higher leel of confidence in terms of arriving and articulating the research's conclusions (James, Milenkiewicz, \& Bucknam, 2007). I am amazed at the cyclical process that comprises participatory action research due to the fact that it allows for flexibility and initiates solution as a response to a certain problematic issue. Compared to other research methodologies, anyone who makes use of the participatory action research would be able to witness its flexibility and beneficial as well as tangible results. As a matter of fact, it is also capable of turning the so-called "imprecise beginnings" into something more refined, more certain and more precise which happens throughout the entire research process (James, Milenkiewicz, \& Bucknam, 2007). Nevertheless, there is a warning for the researchers when it comes to distinguishing between the action research as well as other types of methods and risks in regard to becoming 'meaningless', as in the process, this mainly impedes progress for this impressively effective professional learning tool (Mills, 2003). 
In terms of my personal research paradigm, I believe that I am more inclined towards a constructivist and interpretevist paradigm. Having said this, I think that it fits well the action research methodology because it is quite flexible and has a very compatible approach; it makes use of mixed methods research and is capable of integrating data within different stages in any research inquiry (James, Milenkiewicz, \& Bucknam, 2007; Somekh \& Lewin, 2005). There is no doubt that action research serves as the ideal vehicle in terms of clarifying deeper implications that were revealed based on specific research data conducted through either qualitative or quantitative research approaches. It is also capable of producing quality information and data that offers specific research advantages to the person conducting the research (Somekh \& Lewin, 2005).

As a researcher, it is my desire to not only fulfill my functional role as a teacher but to also serve as a legitimate and reliable voice that is capable of generating theories and knowledge that are applicable in the improvement of my work context. My desire is to ultimately make use of a research process that is reliable, ethical and dependable in terms of providing precise solutions and answers to my role's needs. Most of all, in my attempt to further expand my role and function into something more beneficial to the school communities surrounding me, I intend to make use of research methodologies and adopt research paradigms that reflect my entire being as a person. It is with certainty that I will assert that I will always be employing and utilizing research methods that reflect the person that I am. My judgment on what is the best research method to use will always be based on my own personal subjectiveness brought about my learnings, experiences, personal beliefs and principles as a person.

\subsection{CONCLUSION}

To conclude, there is indeed truth to the statement "the researcher you are is the person you are" because there is no person that is capable of conducting research studies would not be influenced by his or her own personal experiences, beliefs and learnings in the past. To a certain degree, each and every researcher, regardless of his or her profession would always be conducting research based on what he thinks and deems is the best research paradigm and method to adopt. Every researcher makes use of his or her judgment and it is inevitable for him/her to be influenced by such biases. Nevertheless, this does not mean that it works to the advantage of the researcher because more often than not, a research proves to be effective despite being influenced and shaped by these entire distinctive human past experiences. There is no single formula when it comes to conducting research and the beauty of this is that every researcher may be able to freely exercise his or her judgment regarding the research he or she is conducting for as long as the research benefits a larger community.

\section{References}

1. Clark, J. (1994). Objectivity, Subjectivity, and Relativism in Educational Research. Curriculum Inquiry, 24(1), 8194 .

2. Cresswell, J. (2008). Educational research: Planning, conducting and evaluating quantitative and qualitative research (3rd Ed.). Upper Saddle River, N.J.: Pearson Education.

3. Freimuth, H. (2009). Educational research: An introduction to basic concepts and terminology. UGRU Journal, 8 , 7-8.

4. Gale, T. (1998). Methodological 'maps' and key assumptions: A framework for understanding research. Unpublished paper. Central Queensland University.

5. Gibson, I., Allen, G., Sturman, A., \& Danaher, P.A. (2008). Research methods in Education: Study Book. Toowoomba: University of Southern Queensland, Australia.

6. James, A., Milenkiewicz, M., \& Bucknam, A. (2007). Participatory Action Research for Educational Leadership: Using Data-Driven Decision Making to Improve Schools. Thousand Oaks: SAGE.

7. Kemmis, S. \& McTaggart, R. (2005). Participatory action research: Communicative action and the public sphere. In N.K. Denzin \& Y.S. Lincoln, (Eds). The Sage handbook of qualitative research (3rd ed., pp. 559-604). Thousand Oaks, California: Sage Publications.

8. Mackenzie, N. \& Knipe, S. (2006). Research dilemmas: Paradigms, methods and methodology. Issues In Educational Research, 16(2): 193-205.

9. McFarland, K. P., and Stansell, J. C. (1993). Historical perspectives. In L. Patterson, C. M. Santa, C.G. Short, and K. Smith (Eds.) Teachers are Researchers: Reflection and action (pp.10-20). Newark, DE.: International Reading Association.

10. Merriam, S. (2001). Qualitative research and case study applications in education. San Francisco, USA: JosseyBass Publisher

11. Mills, G.E. (2003). Action research: A guide for the teacher researcher (2nd ed.). Upper Saddle River, N.J.: Merrill/Prentice Hall.

12. Moody, D. (2002). Empirical research methods. Retrieved www.idi.ntnu.no/ ekaterip/dif8916/Empirical\%20Rese5arch\%20Methods\%20Outline.pdf

13. Plano Clark, V. \& Creswell, J. (2008). The mixed methods reader. Thousand Oaks, California: Sage Publications.

14. Pring, R. (2004). Philosophy of educational research (2nd Ed.). London, U.K.: Continuum.

15. Richardson, R. (2001). Teoria e Prática da Pesquisa Ação [Theory and Practice of Action Research]. João Pessoa, Brazil: Universidade Federal da Paraíba. (English version).

16. Richards, K. (2003). Qualitative inquiry in TESOL. New York, USA: Palgrave Macmillan.

17. Somekh, B. \& Lewin, C. (2005). Research Methods in the Social Sciences. London, England: SAGE Publications

18. Somekh, B., \& Lewin, C. (2011). Theory and Methods in Social Research. Thousand Oaks, California: SAGE Publications.

19. Wallen, N. \& Fraenkel, J. (2001). Educational research: a guide to the process. New Jersey, USA: Lawrence Erlbaum Associates.

(c) (i) This work is licensed under a Creative Commons Attribution 4.0 International License. 